\title{
Atualização para o controle do câncer no Brasil
}

\author{
Update for cancer control in Brazil
}

Luiz Claudio Santos Thuler', Anke Bergmann²

A ampliação do acesso dos profissionais de saúde ao conhecimento sobre o câncer tem sido um dos objetivos cardeais do Instituto Nacional de Câncer (INCA) nos seus mais de 70 anos de existência.

A Coordenação de Educação do INCA, ciente de sua responsabilidade no desenvolvimento de ações educacionais que atendam à sua missão institucional, desenvolveu um projeto cujo objetivo foi identificar a demanda de qualificação em oncologia para as diferentes categorias de profissionais de saúde, nas diversas regiões do país. Considerando a demanda relatada pelos fisioterapeutas, foi ressaltada a necessidade de qualificação em atenção oncológica por acreditarem ser importante que esses profissionais sejam treinados para detectar, orientar e saber para onde encaminhar o paciente com suspeita de câncer, tendo em vista sua limitada atuação na atenção básica. Segundo alguns profissionais, a temática da atenção oncológica deveria ser mais frequentemente abordada nas matrizes curriculares dos cursos de graduação.

Visto isso, a Coordenação de Educação do INCA apresenta o "Curso de Atualização em Abordagens Básicas para o Controle do Câncer $\mathrm{ABC}$ do Câncer" que, ao se utilizar de tecnologias de Educação a Distância, objetiva, consolidando as políticas governamentais de educação em saúde, oferecer um conjunto de informações básicas e objetivas que facilitem o entendimento da dimensão do câncer, das medidas para o controle da doença e das estratégias de governo para o enfrentamento do problema.

O curso é totalmente a distância, gratuito, com trinta horas de duração, sem tutoria. Destina-se a profissionais de nível superior não especializados em oncologia e a alunos dos cursos de graduação e pós-graduação na área da saúde.

Para a realização do curso, os interessados deverão realizar sua inscrição no sítio www.inca.gov.br, no menu "Cursos e Eventos". O período de inscrições é de 01 a 20 de cada mês, e a realização do curso será no mês subsequente. Os certificados de participação para os aprovados podem ser emitidos on-line, no ambiente virtual de aprendizagem, pelo próprio participante.

Os professores interessados em utilizar o material didático como parte do conteúdo de sua disciplina poderão solicitar, gratuitamente, a publicação impressa para a distribuição entre os alunos e o DVD com o material de apoio ao professor. Para tal, solicitamos encaminhar um ofício com as seguintes informações: nome completo da instituição; nome e endereço postal do(s) professor(es) responsável(is); curso de graduação e a disciplina em que será utilizado o material; relação nominal dos alunos, por disciplina e por curso; quantidade de exemplares necessários para disponibilizar na(s) biblioteca(s) da instituição e endereço postal para a entrega do material. Mais informações podem ser obtidas pelo endereço: ead@inca.gov.br. 